\title{
FILHOS DA TERRA E FILHOS DA SANTA: MANIFESTAÇÕES DE UM TERRITÓRIO CATÓLICO OUILOMBOLA NA FESTA \\ DE SANTA TERESA EM ITAMATATIUA-MA
}

\section{CHILDREN OF THE LAND AND CHILDREN OF THE SAINT: MANIFESTATIONS OF A CATHOLIC QUILOMBOLA TERRITORY IN THE FEAST OF SANTA TERESA IN ITAMATATIUA-MA}

\author{
Katerina Chatzikidi*
}

Introdução

0 festejo anual de Santa Teresa em Itamatatiua, que acontece nos dias $14,15 \mathrm{e}$ 16 de outubro, é uma celebração da santa padroeira da comunidade, Santa Teresa de Jesus. As preparações para a festa começam a partir de julho ou agosto. Entre as mais importantes preparações estão as saídas para o recolhimento de doações para a realização da festa, chamadas "joias".

Numa manhã quente e seca, do ano 2015, apenas alguns dias antes da festa começar, o Batuque (grupo que coleta as joias) saía para uma das últimas coletas. Caminhando pela MA-106, a estrada que liga Alcântara a vários povoados do interior e à Baixada Maranhense (região a oeste e sudeste de São Luís), eles coletavam doações das casas ao longo da estrada.
De lá começam as ruas estreitas de piçarra, nos dois lados do asfalto como artérias empoeiradas, que levam às diversas comunidades que se encontram no interior.

Indo para o leste, com o objetivo de visitar alguns quilombos que cercam Itamatatiua daquele lado, o grupo ouviu uma mulher chamando e virou para olhar. Ela estava em pé, na frente de sua porta, acenando para o grupo que havia passado por sua casa apenas alguns minutos antes. Será que ela não havia saído a tempo? Em dúvida sobre o motivo do chamado, Bena perguntou à mulher, do lugar onde estava:

- Moça, você é crente?

- Não!

- Recebe [a] Santa Teresa?

- Recebo, sim.

\footnotetext{
* Doutora em antropologia social e cultural pela Universidade de Oxford. Vinculada ao Stipendiary Fellow no Institute of Latin America Studies - ILAS na Universidade de Londres (Londres/ING), também é Associada de Pós-doutorado na Universidade de Oxford (Oxford/ING).
} 
Depois de assegurar-se de que era uma casa amigável, o Batuque virou e caminhou em direção à porta da mulher. Ela recebeu a todos calorosamente. É realmente raro que as caixeiras (as mulheres que tocam as "caixas de Santa Teresa", como são chamados os tambores tocados durante o festejo), ou alguém dos homens que estão acompanhando o Batuque, não saibam qual fé religiosa é seguida em cada uma das casas. Por meio de redes familiares e de amigos, eles ficam informados sobre conversões recentes. A maioria das caixeiras e os que as elas se juntam também ganham experiência com as arrecadações de joia anteriores. Com poucas exceções, como a acima descrita, as caixeiras e os escoteiros que as acompanham, sabem com precisão qual casa está, ou não está, ocupada por crentes. Ou seja, eles sabem com precisão onde são e não são bem-vindos.

Em uma das saídas para joia, em 2015, tanto o Batuque como os católicos da comunidade de Oitiua muito discutiram sobre a influência crescente da Assembleia de Deus no povoado. No percurso da caminhada do Batuque pela comunidade recolhendo joia, houve ruas inteiras onde o Batuque não recebeu nenhuma doação. "Todas as casas dessas ruas são evangélicas”, seu Reginaldo que estava acompanhando o Batuque naquele dia falou: "É melhor não gastar mais tempo por aqui”, ele sugeriu. Dado o calor implacável, o grupo deixou de passar por algumas ruas, e as caixeiras também ficaram desanimadas com o fato de que não eram mais bem-vindas naquelas casas. "Tá vendo essa casa aqui?”, Be- nedita, uma das caixeiras falou para mim quando estávamos passando por algumas das "casas evangélicas”, "essa mulher sempre foi devota da Santa...durante toda sua vida. E agora virou crente!”.

No entanto, para muitas pessoas a convicção religiosa não está defınitivamente estabelecida e muitas vezes muda rapidamente. Pessoas que eram católicas durante toda sua vida se converteram a uma igreja pentecostal - ou alguns membros da família se converteram e a casa de modo geral recusa-se a receber a visita da Santa, ou pessoas que haviam se convertido "deixam a comunidade evangélica” e voltam a ser católicas. Portanto, algumas vezes, o Batuque sentese obrigado a perguntar aos donos da casa, apenas para ter certeza e evitar algum confronto. "Eles [os evangélicos] não gostam. Se nos aproximamos de uma casa eles não abrem a porta. Alguns podem até dar joia. Mas a maioria aproveita para sair e começar a gritar e a nos xingar", relatou Benedita.

De uma das casas evangélicas um jovem saiu à porta e chamou: "Ô vocês! Vêm aqui ô!”. As mulheres ficaram surpresas sabendo que o homem era evangélico, mas vendo que ele estava acenando para elas, decidiram caminhar em sua direção. "Eu posso ser crente agora, mas desde que eu me lembro, nossa casa sempre recebia a Santa e dava joia. Então, aqui está a minha joia para vocês". 0 homem sorriu e desejou um bom dia para o Batuque. As mulheres agradeceram e seguiram em frente. Parecia que para aquele evangélico ${ }^{1}$, as saídas para joia faziam mais parte de uma tradição

1. Na linguagem coloquial em Alcântara, o termo "evangélico" descreve qualquer denominação cristã não católica: de evangélicos pentecostais a Testemunhas de Jeová. Neste artigo, portanto, também usarei esse termo para referir-me a qualquer denominação não católica embora discutindo principalmente evangélicos pentecostais (predominantemente integrantes da Assembleia de Deus). Quero agradecer a Marcos Todeschini pela revisão ortográfica deste artigo. 
local compartilhada por todos, que uma celebração estritamente católica (e, portanto, "proibida” ou “pecaminosa”). As caixeiras ficam contentes que alguns "crentes" ainda reconheçam "a importância que nossa festa tem para todas essas terras”, como falou Dona Irene, tocada pela consideração do homem.

\section{Contexto etnográfico}

Itamatatiua é uma comunidade negra rural quilombola de cerca de 500 pessoas, situada às margens da costa atlântica maranhense, onde os morros se transformam em “ilhas” na estação chuvosa (verão). Localizada no extremo sul do município de Alcântara, é uma das comunidades mais afastadas do Centro de Lançamento (CLA) construído na área municipal. Itamatatiua é bem conhecida na região, principalmente por duas razões: o festejo católico de outubro e a produção de artesanato de cerâmica.

A maioria dos itamatatiuenses se autoidentifica como negros e quilombolas. Eles também se autoidentificam como "filhos da Santa”, algo que faz com que a sua relação com a Santa Teresa seja um aspecto intrínseco da identidade social e individual. A história da fundação da comunidade, tal como relatada pelos moradores, tem diferentes versões (PEREIRA JÚNIOR 2012). Porém, todas as narrativas ilustram, sem deixar dúvidas, que tenha sido a Santa Teresa que escolheu tanto o sítio quanto as pessoas - a população: a própria Santa os convidou a morar nas suas terras e prometeu cuidá-los. Por meio desse ato, eles se tornaram filhos dela, e prometeram morar lá, cuidar das terras da Santa e reverenciá-la. Concretizando e protegendo os laços de parentesco entre as duas partes pelas futuras gerações, o povo de Itamatatiua adotou o sobrenome da Santa, chamada localmente Santa Teresa de Jesus. Conforme relatos de residentes, o sobrenome "de Jesus” foi passado pelos próprios fundadores da comunidade até a presente geração. Como frequentemente comentam: "Todo mundo que nasceu aqui tem o sobrenome 'de Jesus'”.

Davi Pereira Júnior, filho da terra e antropólogo que realizou trabalho de campo na comunidade, sugeriu que a adoção do sobrenome da Santa é mais que "um fator identitário" e precisa "ser visto como meio de reforçar os laços sociais com a Santa e com a terra" (PEREIRA JÚNIOR, 2011, p. 96). Foi precisamente por meio do estabelecimento de laços de parentesco com a Santa, que os itamatatiuenses tornaram-se e seguem sendo os legítimos moradores das terras de Santa Teresa.

A questão da relação familial entre os moradores e a Santa torna-se particularmente relevante quando analisada dentro do contexto local mais geral, caracterizado por grande insegurança fundiária. Apesar da maioria das quase 200 comunidades quilombolas do município terem recebido a certificação emitida pela Palmares, ${ }^{2}$ nenhuma delas recebeu a titulação definitiva do seu território. A implantação do Centro de Lançamento de Alcântara (CLA), uma das grandes "obras de desenvolvimento" do chamado avanço tecnológico, causou

2. A Fundação Cultural Palmares (FCP) é uma entidade vinculada ao Ministério da Cultura e voltada para promoção da arte e da cultural afro-brasileira. Entre as suas principais funções está a emissão de certificações para comunidades quilombolas. 0 documento emitido reconhece os direitos das comunidades quilombolas e dá acesso aos programas sociais do Governo Federal. 
o deslocamento forçado de 23 comunidades quilombolas em 1986-7, e desde então continua sendo uma constante fonte de insegurança territorial no município. Como aponta Serejo Lopes (2012, p. 1), militante do Movimento dos Atingidos pela Base Espacial de Alcântara (MABE), "no município de Alcântara convivem de forma antagônica duas realidades bastante distintas. De um lado tem-se o governo brasileiro, representado pelo projeto de origem militar materializado na base espacial ... e de outro, as comunidades quilombolas que ocupam e vivem lá desde os tempos da escravidão. Ambos reivindicando o mesmo território".

0 CLA, com seus planos de expansão, já foi apontado na literatura antropológica como o antagonista por excelência das comunidades negras rurais quilombolas no município (SAULE JÚNIOR 2003; SAULE JÚNIOR e CARDOSO, 2005; ALMEIDA, 2006; ANDRADE, 2006; OLIVEIRA BRAGA, 2011; NUNES, 2011; PEREIRA JÚNIOR, 2012). Sem pretender diminuir a importância que a existência do CLA tem para todos os quilombos do município, incentivando a organização política da luta fundiária quilombola, e levando em consideração os dados recolhidos durante os 15 meses de minha pesquisa de campo, defendo aqui que no caso das terras de Santa Teresa surgem outros desafios que afetam diretamente os direitos territoriais quilombolas. Para a maioria dos moradores católicos do território da Santa, a recém-chegada presença pentecostal (predominantemente a da Assembleia de Deus), que nega os laços entre a Santa, os moradores e o território, aparece como uma grande ameaça territorial. Essa negação é uma oposição direta a regras estabelecidas, há muitas gerações, pelo “encarregado/a das terras” cargo hereditário e de extrema importância local. Trata-se da pessoa que tem o papel de cuidar das terras e atuar como intermediário entre a Santa Teresa e os moradores de seu território.

0 território chamado "terras de Santa Teresa” corresponde a cerca de 55 mil hectares: o sul do município de Alcântara e uma parte do município vizinho de Bequimão. Cerca de 40 comunidades quilombolas fazem parte deste território do qual Itamatatiua é o centro simbólico e administrativo. 0 lugar central de Itamatatiua dentro do extenso território da Santa Teresa está refletido, entre outras coisas, na existência da imagem da Santa Teresa na igreja da comunidade. A imagem é considerada como uma representação tangível da própria Santa, e é tratada com a maior reverência e respeito. Apesar de haver outras duas estátuas de Santa Teresa na igreja de Itamatatiua, apenas uma é considerada como a "verdadeira". Na comunidade e até na sede de Alcântara, ouvi várias histórias sobre a Santa Teresa protegendo dos predadores, seus filhos e suas terras. Nelas, infratores ameaçando invadir e ocupar ilegalmente as terras dela, malfeitores discriminando os "pretos da Santa" - como os moradores de Itamatatiua são conhecidos -, frequentemente têm sido encontrados em situações horríveis, ou até mortais, por consequência de intervenção divina destinada a proteger o território, e o povo de Itamatatiua em particular. Tanto a vitalidade da Santa, quanto a sua vontade e persistência de morar em Itamatatiua, estão fortemente manifestadas nessas histórias.

0 Batuque é um grupo que percorre as comunidades dentro e fora das terras de Santa Teresa, recebendo doações de devotos para a organização da festa anual. É composto pela Santa (na forma de uma imagem), duas caixeiras, duas bandeiras (meninas que carregam as bandeiras da 
festa), uma guardiã da Santa (que carrega a imagem), um guia que tem bom conhecimento da área, dos povoados e dos moradores (quem faz os arranjos para dormidas e refeições), e um ou dois escoteiros, que são os que carregam as doações de animais e comida, soltam foguetes para assinalar a localização do Batuque para que os povoados vizinhos saibam que eles estão se aproximando e que também atuam como guardiões do Batuque durante todas as visitas. Nas saídas para o recolhimento de joia, que continuam por meses, o grupo percorre fisicamente o território quilombola da Santa Teresa. De norte a sul e de leste a oeste, a Santa, acompanhada pelo Batuque, visita todas as comunidades do seu território.

No imaginário dos devotos católicos da Santa Teresa, assumir a responsabilidade de morar e cuidar das terras que a Santa lhes conferiu, constitui um acordo muito real e vinculativo, que os justifica - tanto no sentido literal quanto teológico da palavra -, como ocupantes legais desses territórios. Percebemos, portanto, que a identidade (ou autoidentificação) -tanto individual quanto coletiva, através de laços de parentesco com a Santa Teresa -, com o território, numa síntese de direitos e preceitos religiosos e familiais, transpiram-se como indi- visíveis, virtualmente impossível de serem concebidos à parte.

Apesar dos fortes laços históricos com a santa padroeira, o mapa religioso das terras de Santa Teresa, assim como o da sede e outros povoados de Alcântara mudou drasticamente nos últimos anos. Segundo o censo nacional de 2010, dos 21.851 homens e mulheres que compõem a população do município de Alcântara, 12.578 se autodeclararam afiliados à Igreja Católica Apostólica Romana (e 80 da Igreja Católica Apostólica Brasileira), 4.570 se autodeclararam evangélicos de todas as denominações e 4.623 se autodeclararam não-religiosos. ${ }^{3}$ Dos evangélicos, 3.643 se afiliavam à igreja pentecostal Assembleia de Deus. Oito anos depois do último censo, e com o número de igrejas evangélicas ${ }^{4}$ que pontilham o interior de Alcântara crescendo a cada dia, pode-se dizer, com segurança, que o número dos evangélicos também tem aumentado desde 2010.

Nas terras de Santa Teresa, a presença pentecostal e sua pronunciação do princípio que "Santo não tem terra" causa tensão territorial. Outro desafio crítico relacionado a essa presença, mas não restrito a ela, é a usurpação do território por indivíduos por meio de cercas, que ocupa e delimita ar-

3. Segundo o censo de 2010, o (zero) residentes do município de Alcântara declararam pertencer a alguma religião afro-brasileira, como Umbanda, Candomblé ou Tambor de Mina. Dado que eu, pessoalmente, participei em curas de Tambor de Mina, que é uma religião relativamente popular no Maranhão (cf. FERRETTI, S. 1996, FERRETTI, M. 2000, e AHLERT 2011, 2016 sobre Terecô, uma variação de Tambor de Mina), eu não descartaria a possibilidade de os residentes terem dissimulado qualquer afiliação com religiões afro do questionário do censo. É importante ressaltar que religiões de matriz africana não estão presentes em Itamatatiua. Sobre práticas de esconder religiosidade afro, ver: BASTIDE [1960] 1989, p. 219-240, FRY 1977.

4. Quase exclusivamente Assembleias de Deus. Há algumas outras igrejas pentecostais em Alcântara, como a Primeira Igreja Batista em Alcântara e a Igreja Adventista do Sétimo Dia, mas sua presença no interior é virtualmente não-existente -particularmente em relação à presença ubíqua da Assembleia de Deus. Vale mencionar que atualmente não há nenhuma igreja neo-pentecostal em Alcântara (como, por exemplo, a nacionalmente poderosa Igreja Universal do Reino de Deus - IURD). 
bitrariamente o espaço dentro dos limites do território quilombola. As lideranças da comunidade continuam resistindo e reivindicando a titulação do território frente aos órgãos estaduais e federais que possam regularizar e titular o seu território. A área de Itamatatiua entrou no processo de regularização fundiária pelo INCRA em 2012. 0 processo ainda está em andamento, assim como o da maioria das comunidades do interior de Alcântara.

Diante do lento processo da regularização fundiária e da ausência da titulação definitiva das terras da comunidade, muitos moradores persistem na luta pela defesa do território por meio de práticas culturais e religiosas. Como tentarei sustentar nas páginas que seguem, o festejo anual de Santa Teresa em Itamatatiua manifesta-se como uma dessas formas de luta cotidiana. Atravessando milhares de hectares para visitar as centenas de casas localizadas dentro do território, o Batuque está mapeando fisicamente as terras de Santa Teresa. Dessa forma, a maioria dominante católica quilombola está se agregando à população não católica, manifestando sua oposição à expansão evangélica e sua determinação para manter as terras de Santa Teresa de uso comum.

0 presente artigo, tem como foco algumas formas nas quais os laços religiosos e territoriais, entre os moradores dos povoados que compõem as terras de Santa Teresa, são reforçados e reafırmados durante o festejo da santa padroeira. Para esse fim, discutirei as atividades que giram em torno da organização da festa católica anual em homenagem a Santa Teresa de Jesus (também conhecida como Santa Teresa d'Ávila) em Itamatatiua. Será argumentado que durante os meses de preparação para essa festa religiosa, os laços históricos que unem os quilombos dentro do território partilhado estão reafirmados através de atos de devoção à santa católica. Tais demonstrações públicas de fé religiosa, parafraseando Latour (2005), não apenas reagregam o social das terras de Santa Teresa, como também manifestam este social contra os seus antagonistas religiosos e territoriais.

A análise voltada, quase exclusivamente, ao festejo de Santa Teresa não se deve ao fato de ele ser o único evento no calendário católico religioso em Itamatatiua, mas ao fato de ele ser o maior e o mais emblemático entre as outras manifestações. Juntamente com a produção de cerâmica de Itamatatiua (discutida em CHATZIKIDI, 2018), as ações coletivas em torno do festejo são uma das armas proeminentes da "resistência cotidiana" quilombola (SCOTT, 1985). No entanto, em contraste às dinâmicas participativas restritas aos atores envolvidos na produção de cerâmica (um grupo de mulheres), a forma de captar herança (neste caso, religiosa) é popular e abrangente, assumindo uma forma de participação em massa durante os dias de festa. Assim como na produção de cerâmica, a festa religiosa tem fortes conexões simbólicas e tangíveis com a terra. Porém, a festa diz respeito muito mais a delimitar uma geografia partilhada chamada "terras de Santa Teresa”, e muito menos sobre a discorrer sobre as qualidades materiais da terra da qual essa geografia é composta. $\mathrm{Ou}$ seja, se a cerâmica está intrinsecamente ligada à terra, a festa constitui e articula o território partilhado.

Levando em consideração a difusão da presença evangélica na região, argumento que a festa, além de ter um propósito estritamente religioso (devoção à santa padroeira), vale-se, ao mesmo tempo, de uma herança religiosa partilhada. Num contex- 
to sociorreligioso em rápida mudança, um dos funcionamentos principais da festa é o de renovar as afiliações dos membros da família de Santa Teresa (os católicos que moram no seu território) e reafirmar as reivindicações territoriais católicas/ quilombolas. Por meio da sua realização, a festa demonstra a presença católica e o seu controle efetivo sobre a terra. 0 processo de recolhimento de joia também demonstra a reação católica à negação (e até escárnio) do culto aos santos, de suas expressões culturais e religiosas, e de sua soberania sobre o seu território.

Para os fins deste artigo, e sem aprofundar o funcionamento interno dos rituais religiosos, considero o ritual como "um aspecto de todo comportamento social, não um tipo de comportamento especial, embora alguns tipos de comportamento sejam muito mais ritualistas que outros" (MacGAFFEY, 1986, p. 42). 0 foco aqui será a ocorrência pública de tais rituais e sua visibilidade vis-à-vis, o que para muitos católicos são os seus antagonistas religiosos e territoriais. Portanto, no que diz respeito à exegese ritual, simplesmente "desligarei o dispositivo de busca de intencionalidade" (BLOCH, 2005, p. 132) e darei um zoom de afastamento, a fim de enfatizar a intencionalidade da participação no ritual como uma afirmação consciente e corporal do controle territorial.

Tampouco serão aprofundadas as tensões decorrentes entre católicos e evangélicos nas terras de Santa Teresa, no espaço limitado deste artigo. 0 principal objetivo é discutir algumas das principais iniciativas tomadas por uma grande parte dos moradores para proteger o território e o estilo de vida coletiva que consideram intrinsicamente católico. Ele visa demonstrar que nos preparativos e durante a festa de Santa Te- resa, rituais "tradicionais" - como o toque de caixa - assumem uma nova dimensão da qual os devotos católicos estão cientes. Isto consiste em um meio de intervenção em massa e em um mapeamento do território coletivo, que permite a visibilidade e a manifestação da presença católica, ainda predominante, e do seu controle sobre o território quilombola.

\section{Os filhos e os outros}

0 crescimento da população é apontado por muitos quilombolas como uma das principais razões por trás da crise habitacional que está sendo observada nos últimos anos em Itamatatiua e comunidades vizinhas. Cada vez mais, pessoas precisam de um terreno para construir suas casas, mas isso é algo que parece ser cada vez mais difícil de conseguir. A chegada de "pessoas de fora", como os quilombolas chamam aqueles que se juntam à população local, que demarcam de forma anárquica terrenos, desconsiderando o direito consuetudinário, agravou esse problema. Isso porque se alguém precisa da terra, o seu "proprietário" prefere vendê-la em vez de concedê-la. "Mas como eles vendem [um terreno] se a terra não pertence a eles? Essa terra não é deles...A Santa que é a dona”, disse Dona Luísa de Itamatatiua explicando-me sua oposição às ilícitas vendas de terra quilombola.

Os moradores mais antigos apontam os crentes como invasores eminentes em virtude de sua rejeição vociferante do pacto entre a Santa Teresa e os seus filhos (católicos). 0 problema com a usurpação do território coletivo e sua apropriação privada cresceu especialmente nas áreas fora do centro principal de Itamatatiua (chamado "sítio"), onde a autoridade da encarregada das terras não é sentida imediatamente. 
Dona Maria de Jesus, uma das moradoras mais idosas, teve uma experiência pessoal com esse problema quando, como vários outros moradores de idade, ela decidiu mudar-se para fora do sítio para poder ter mais fácil acesso à estrada (MA-106). Ela contou:

Essa terra dessa Santa era muito grande. ... Santa Teresa já tinha muito, mas não tem mais terra...pouquinho...só esse trechinho aqui. ô, só pra tu ver ... eu tô morando aqui, mas esse terreno eu comprei. Antigamente ninguém comprava. Hoje, tem outro que tem casa e aí quando aparece um terreno eles vão tirando...tirando os terrenos pra vender.

Pela maioria esmagadora da população quilombola que habita as terras de Santa Teresa, "comunidade e catolicismo são indissociáveis” (BOYER, 2016, p. 29). É por esse motivo que a presença de evangélicos - na sua maioria integrantes da Assembleia de Deus -, é percebida como incompatível dentro do território quilombola de Santa Teresa. Como muitos moradores comentam, antes da chegada dos evangélicos "toda essa área era católica”. “Já não é mais como era”, Zé Roxo falou para mim enquanto estávamos caminhando em Itamatatiua onde ele mora. "Quando nós nos entendemos, quando eu me entendi, não existia nenhum crente aqui nesse trecho", disse ele apontando a vasta área aberta do campo que se esticava à nossa frente. "Você consegue imaginar?", perguntou retoricamente enquanto olhava para frente.

Os evangélicos que vivem nas terras de Santa Teresa rejeitam o axioma de que essa terra pertence à Santa (que, pelos católicos, é a original e única proprietária) e não adotam a ética do uso comum da terra, que os filhos adotam há muitas gerações. Esses dois pontos de disjunção são de grande importância para os filhos de Santa e para os quilombolas de Itamatatiua, em particular.

Ao enfatizar como a Santa "costumava possuir muita terra, mas não mais”, os católicos estão destacando o quanto a presença evangélica em seu território coletivo foi experimentada como intrusiva e aniquiladora.

Reagindo contra a crescente "ameaça" evangélica, os itamatatiuenses, na vanguarda da vida religiosa nas terras de Santa Teresa, tomam iniciativas para reforçar o catolicismo e os laços religiosos entre os católicos. Isto, como será explorado a seguir, ocorre principalmente por meio da realização de diferentes ritos que fazem parte das festividades religiosas. Nas palavras de Durkheim ([1912] 2001, p. 287): “os ritos são, acima de tudo, os meios pelos quais o grupo social se reafirma periodicamente". Como analiso em outro texto (CHATZIKIDI, 2018), a herança "etno-cultural" de Itamatatiua, derivada da, e afırmando a, relação histórica com "territorializações específ1cas” (ALMEIDA, 2006), é uma das mais importantes formas de ação política de base (grassroots) em defesa do seu território coletivo. A sua identidade religiosa, em virtude da sua associação intrínseca com o parentesco e o território, é outra. Assim como a identidade cultural está ligada às qualidades materiais da terra que eles habitam (o barro preto de quem são feitas as pessoas e a cerâmica), a sua identidade religiosa está ligada à trindade: Santa (catolicismo), terra de Santa (territorialidade) e filhos da Santa (parentesco).

\section{A herança do cristianismo da libertação}

Itamatatiua vem construindo uma consciência cada vez maior como comunidade 
quilombola ${ }^{5}$ e orgulha-se de suas distintas tradições étnico-culturais ${ }^{6}$. Especialmente nos últimos 15 anos, a renovação da prática de cerâmica (NORONHA, 2015) e a aclamação local para a realização de danças como Tambor de Crioula, contribuíram para a consolidação de uma forte consciência e orgulho na história e no patrimônio cultural da comunidade. Isto não é interpretado como distinto de, mas em conexão e aliança com a igreja católica. Neste caso, portanto, "o catolicismo surge em sua verdade histórica como um 'movimento' em vez de uma doutrina, um movimento vasto, minuciosamente especializado na arte da assimilação, o que cria algo novo, mas em que nada é perdido" (LEFEBVRE, 2014, p. 244). Para muitos itamatatiuenses, o catolicismo forneceu e continua fornecendo um porto seguro para a preservação e a continuação de uma ampla gama de práticas culturais e religiosas.

Ramon Sarró (2008, p. 81) apresenta um contundente argumento sobre a "aliança entre cristianismo e 'costume'" em sua discussão sobre os Baga na Guiné. Naquele contexto etnográfico, e enfrentando taxas crescentes de conversão ao islamismo, muitos Baga optaram pela conversão ao cristianismo, pois eles sentiram que dessa forma poderiam proteger suas tradições religiosas e étnicas. Ao contrário da "força modernizadora" do islamismo, no contexto de Guiné, o cristianismo não proibiu os rituais e outros costumes dos Baga (p. 78).
Considerando-se tudo isso, o cristianismo católico, assim como praticado em lugares como Itamatatiua, também emana a ideia de uma igreja que permite uma relativa liberdade de expressão religiosa e cultural se comparada às rigorosas proibições e regras rígidas da maioria das igrejas pentecostais. De forma significativa, a aliança política entre membros da igreja católica e movimentos afro-brasileiros (particularmente na década de 1990), em Alcântara, também contribuiu para a criação de um imaginário por meio do qual a igreja católica defende e deseja fortalecer quilombolas e suas tradições culturais. Se Itamatatiua se tornasse evangélica, deixaria de tocar as caixas de Santa Teresa, não haveria Tambor de Crioula, Forró de Caixa, ou Dança do Negro e outras manifestações culturais ligadas à cultura afro-brasileira local e, claro, não haveria festa de Santa Teresa. É em grande parte devido à influência dos movimentos negro e quilombola, bem como dos missionários imbuídos de ideias da chamada “Teologia da Libertação”, que a Itamatatiua resiste categoricamente em não deixar tais crenças e práticas.

A partir de meados da década de 1950 até o final da década de 1980, setores da igreja católica no Brasil gradualmente adotaram teorias marxistas e trabalharam lado a lado com os pobres e desamparados em todo o país. Particularmente durante os anos da ditadura militar (1964-1985), membros da igreja católica no Brasil tiveram um

5. Com isso quero dizer que uma forte identificação com uma identidade étnica negra que foi moldada sob a influência de movimentos negros e quilombolas ao longo de décadas. Além disso, Itamatatiua se orgulha da denominação comum da comunidade, por alcantarenses, como um quilombo "de verdade" em virtude da maioria dos residentes terem tez mais morena que a maioria dos quilombos alcantarenses. Os quilombolas de Itamatatiua se orgulham também das denominações "pretos” e "pretos da Santa”, se livrando das anteriormente conotações pejorativas da palavra preto.

6. cf. PEREIRA JÚNIOR, 2012. 
papel fundamental na disseminação, especialmente em áreas rurais e no Nordeste, do que Michael Löwy (1996) chamou de "Cristianismo da Libertação" um movimento sociorreligioso profundamente influenciado por ideias e valores igualitários que depois serviram como base teórica para a teologia da libertação. Entre outras coisas, Lôwy contribuiu para o surgimento de um forte movimento de consciência negra católica (FRENCH, 2007; BURDICK, 1993). As então formadas Comunidades Eclesiais de Base (CEBs) abraçaram críticas de teorias pedagógicas e marxistas e contribuíram para a consolidação de uma educação política liberal, especialmente entre os pobres rurais do Brasil (DULLO, 2013). Elas também forneceram conhecimentos práticos para a mobilização política, tendo uma influência forte sobre as formas em que os quilombolas e outros camponeses manifestaram suas preocupações e se organizaram em defesa de seus direitos.

Em Alcântara, o papel da igreja católica e suas missões nesses anos deixaram uma marca indelével na luta dos quilombolas pelos seus direitos territoriais. Sob a jurisdição da Prelazia de Pinheiro (promovida a Diocese em 1979), missionários brasileiros e estrangeiros realizaram longos períodos de trabalho missionário nas comunidades e cidades da Baixada Maranhense. Especialmente durante os anos sob a direção do bispo Dom Afonso Maria Ungarelli (1946-1975), o trabalho dos missionários da $\mathrm{MSC}^{7}$, foram de grande importância para a conscientização dos direitos humanos, estabelecendo uma base sólida para a luta política quilombola nas décadas se- guintes. Vários sacerdotes e agentes pastorais também assumiram um papel ativo na luta dos quilombolas contra o centro de lançamento, defendendo as reivindicações dos moradores e ajudando-os a organizar sua causa.

Desde o início da década de 1980 até hoje, clérigos e conselheiros leigos em $\mathrm{Al}-$ cântara, em grande parte, uniram forças com os quilombolas na articulação de suas posições. Militantes dos movimentos negro e quilombola tiveram uma estreita colaboração com missionários e sacerdotes católicos em Alcântara, e continuam a ter um bom relacionamento entre si, ao contrário dos pastores e igrejas evangélicas em geral. 0 trabalho da igreja católica, influenciado pelo cristianismo da libertação contribuiu para a construção de um perfil de igreja de aceitação, dos pobres e marginais, e de todos aqueles menos privilegiados em geral. Löwy chama a atenção para o fato de que este não era um fenômeno exclusivamente brasileiro, mas difundido em toda a América Latina, onde a "igreja dos pobres é a herdeira da rejeição ética do capitalismo pelo catolicismo" - produto de "afinidade negativa”, em termos Weberianos, entre os dois (LÖWY, 1996, p. 30).

Isto torna-se particularmente importante, em contraste com a "cultura conservadora político/religiosa dominante da maioria das igrejas evangélicas", que "muitas vezes as transforma em defensores passivos ou fervorosos do status quo e, às vezes, até mesmo de ditaturas militares sinistras, como as do Brasil, do Chile e da Guatemala” (LÖWY, 1996, p. 113). Conhecidas por suas poderosas alianças políticas e riqueza acumulada

7. Significa Missionários do Sagrado Coração. É uma congregação religiosa da igreja católica que foi fundada na França em 1854. Na Diocese de Pinheiro, os missionários eram principalmente italianos e depois canadenses. 
(FRESTON, 1994; CARNEIRO, 2011; MACHADO e BURITY, 2014), este aspecto das igrejas evangélicas se reflete fortemente nas percepções populares em Alcântara sobre a recente "infiltração" de evangélicos em suas comunidades. No entanto, precisamos ressaltar que o cristianismo da libertação tem sido apenas uma vertente da igreja católica no Brasil, e que atualmente está longe de ser a predominante.

A igreja católica em Alcântara continua simpatizando com os movimentos políticos nos quais os quilombolas estão participando e o legado das CEBs está profundamente arraigado nas práticas de mobilização política camponesa entre os quilombolas. Em Itamatatiua, o trabalho dos missionários católicos de influência marxista encontrou terreno fértil na própria trajetória histórica da comunidade e na sua profunda ideia de pertencimento ao território coletivo. Vários sacerdotes passaram temporadas em Itamatatiua contribuindo não apenas para a educação religiosa dos quilombolas, mas também para a educação política e de direitos humanos. Padre Haroldo, por exemplo, continua trabalhando em estreita colaboração com Neide de Jesus, atual encarregada das terras e presidente da associação dos moradores. Ele abraçou abertamente a luta da comunidade pelos seus direitos à terra. Numa conversa que tive com ele em São Luís, onde reside, o sacerdote expressou a sua posição veemente em relação à presença de um pastor da Assembleia de Deus em Itamatatiua. Ele disse: "Quem entrou agora lá é um protestante, não é? Que não devia. Porque a colônia [sic] é dos quilombolas. Não dele. Tá errado. Isso aí tá errado. É como se eu chegasse lá e fizesse a minha casa. Não. É um quilombo. É um quilombo. É um quilombo", repetia ele, firmemente.
Enquanto a justificativa do Padre Haroldo para o repúdio da presença evangélica dentro da comunidade foi feita sob uma premissa etno-legal (Itamatatiua tendo o status legalmente protegido de quilombo), muitos moradores articulam a sua objeção à presença do pastor na comunidade sob premissa unicamente religiosa (Itamatatiua sendo terra de Santa Teresa e, portanto, por definição exclusivamente católica). "Eu me entendi assim. Eles dizendo que a terra era da Santa. Era da Santa, né? E assim, eu ainda entendo assim", disse Nazaré, moradora de Itamatatiua.

Na próxima seção deste artigo, será discutida a presença física do Batuque pelo território de Santa Teresa. 0 argumento é de que essa presença não só chama os católicos à ação, por meio das suas contribuições para a realização da festa, mas também passa uma mensagem de determinação aos evangélicos. "Bora bater essas caixas bem forte, gente! Bora mostrar que estamos aqui. Santa Teresa está aqui!", disse Benedita quando o Batuque estava entrando numa comunidade.

\section{Mapeando o território partilhado}

Muitas semanas antes da festa começar, o Batuque, oriundo de Itamatatiua, percorre as comunidades dentro e fora das terras de Santa Teresa, a fim de coletar joia. Oferecidas pelos devotos de Santa Teresa, as joias contribuem para a organização da festa. É, portanto, com a ajuda e a contribuição material e imaterial de todos os devotos católicos que habitam as terras de Santa que a festa se realiza todo ano. Começando pelas comunidades mais afastadas de Itamatatiua e aproximando-se, passo a passo, até voltar a igreja do povoado, a Santa (na forma de uma imagem que se acredita ser a própria 
Santa) ${ }^{8}$ acompanhada pelo Batuque, visita todas as comunidades do seu território. Durante essas visitas, que continuam até a véspera da festa, a Santa (como pequena estátua) é cuidadosamente carregada por uma guardiã a fim de "fısicamente" visitar todas as casas de seus devotos e dar-lhes a sua benção.

\section{Teresinha tira joia \\ Mas não é com precisão \\ Ela tira experimentando \\ Quem tá de bom coração \\ Teresinha veio de longe \\ Cansadinha de andar \\ $\mathrm{Na}$ casa deste devoto \\ Ela veio se descansar \\ Senhora dona da casa \\ Teresinha veio lhe ver \\ Se lhe acha com saúde \\ A receba com prazer}

Cantigas como essa são cantadas pelas caixeiras quando estão visitando uma casa para recolher joia. As primeiras saídas, que começam entre julho e agosto, têm como destino as comunidades que estão nos limites exteriores das terras de Santa e, portanto, as mais afastadas de Itamatatiua. Conforme as semanas passam, as visitas se aproximam até gradualmente chegar a Itamatatiua, onde o Batuque realiza o último arrecadamento de joia na véspera da festa. Nessas expedições centrífugas e retornos centrípetos à casa, a soma dos quilômetros caminhados sob o sol equatorial aumenta, enquanto o raio coberto pelo Batuque encurta. Bena, uma das caixeiras, me explicou o motivo alternado das saídas:
Cada tempo, cada semana, sai uma turma por um lado. Primeiramente a gente vai pra cá pro lado de Bequimão, interior de Bequimão. A gente vai às vezes, passa sete dia, oito dia...aí vem, passa três dia em casa aí a outra turma já sai pra cá pro lado de Mojô, pra cá, pra esses lado...as vezes passa dez dia...agora não passa mais, dantes passava dez dia até quinze dia a gente passava. Mas agora o máximo é sete dia, oito dia. Aí vem... aí essa turma vem descansa, essa que tava [em casa] já vai pro outro lado, pra cá pro lado de Japeú, pra aí... Japeú é só três dia. Aí vem, aí a outra turma já tá esperando pra sair pro outro lado. Assim é que é... até chegar o dia da festa. Aí chegou o dia do mastro, aí já vai de manhã, vem de tarde... vai de manhã, vem de tarde todo dia, até no dia 13. Todo dia a gente vai. Aí vai uma turma, fica a outra, aí vai essa, chega a outra... até no final.

O Batuque anuncia a sua chegada numa dada comunidade batendo as caixas de Santa Teresa. Os moradores que estão esperando a visita, ao ouvir os tambores, sabem que a Santa com seu Batuque chegou. Eles abrem suas portas e preparam as suas doações. Quando o Batuque se aproxima, os donos de casa recebem a visita da Santa e abrem caminho para ela entrar. A guardiã que carrega a Santa durante a visita, cuidadosamente entrega a pequena imagem da Santa ao devoto que a recebe. Enquanto a Santa é levada para dentro da casa, todos recebem a suas bençãos, o Batuque bate as caixas, dança e canta cantigas de gratidão pela joia. Após alguns minutos, a dona de casa devolve a Santa e agradece a ela e ao Batuque pela sua visita. Às vezes, os devo- 
tos estão especialmente tão movidos pela visita da Santa Teresa, que começam a chorar ou se agarrar a ela por mais tempo. 0 grupo então, rapidamente, muda a melodia e canta uma cantiga adequada à ocasião. No último caso, por exemplo, elas cantariam um dos seguintes versos:

O sol entra pela porta
E a lua pela janela
Senhora Santa Teresa
Eu não vou daqui sem ela
Senhora me dê a Santa
Que essa Santa eu não lhe dou
Essa Santa não é minha
É do nosso Salvador

Quando a Santa é devolvida à guardiã e as doações são entregues ao porteiro, o Batuque passa para a próxima casa despedindo-se dos devotos cantando bons desejos:

Senhora dona de casa
Eu já vou me retirar
Adeus até paro ano
Eu tornarei a voltar
Fique vós com Deus adeus
Que eu também com Deus me vou
Fique com Nossa Senhora
Com Teresinha eu vou

Percorrendo as planícies das terras de Santa Teresa, o Batuque que carrega a Santa aproveita para amplificar a sua voz e manifestar a sua presença de modo alto e claro. Batendo as caixas de Santa Teresa ao entrar numa comunidade e durante todas as visitas, eles anunciam a sua presença e passam uma forte mensagem à população evangélica. A caixa (e o tambor em geral), instrumento conhecido por ser fortemente desprezado pelos evangélicos, mas que é essencial para o festejo, assume um papel central e simbólico nas saídas para joia e durante a festa. Neste sentido, como a própria festa, a caixa se transforma "numa encarnação da comunidade” (MEYER, 2012, p. 165).

0 toque de caixa é um gesto simbólico que é profundamente percebido por aqueles a quem a mensagem se destina. "O som torna o objeto dinâmico" sustenta Voegelin (2011, p.11). Gallant (1994) analisa um episódio que aconteceu na Kérkyra (Grécia) em 1867, quando camponeses rebeldes se recusavam a pagar aluguel aos donos da terra. Num gesto simbólico que humilhou de maneira profunda os administradores e policiais reunidos, um campesino esvaziou na frente deles uma cesta cheia de chifres de carneiro e ofereceu-lhes no lugar do aluguel. Como sustenta Gallant (p. 704) "a jogada dos chifres simbolizou o corno dos proprietários. Numa inversão de papéis, o aluguel/esposa estava agora nas mãos dos amantes/inquilinos e lá, ela permaneceria”. Perceber os mecanismos de um "sistema cultural de significado" compartilhado (p. 703), é chave para compreender as formas de resistência, de "provocação" ou de demonstração de poder mais sutis. De forma parecida com os chifres que o campesino apresentou na frente dos representantes dos proprietários, as caixas batendo ao ar livre para que todos possam ouvir (tanto católicos como evangélicos) ressoam em uma fonte de compreensões simbólicas que incitam grande alegria para os primeiros e angústia para os últimos (GALLANT, 1994). 0 próprio ato de ouvir "produz um mundo sonoro em que habitamos com ou contra a nossa vontade" (VOEGELIN, 2011, p. 11). Quer eles gostem ou não, o toque de caixa alcança os evangélicos mesmo através de portas fechadas. 0 mesmo certamente pode ser dito para os alto-falantes dos evangélicos que profundamente "provocam" muitos católicos. Porém, 
como já mencionado, essas ações não serão examinadas neste artigo.

Preenchendo o espaço com o seu som controverso, as caixas de Santa Teresa convocam a comunidade católica enquanto instigam a antipatia dos evangélicos. Junto com o som das caixas, o catolicismo se espalha por todo o território de Santa Teresa e, pelo menos durante as festividades, prevalece sobre o culto evangélico. A percussão, defende Hendy (2014, p. 143) "sempre tem sido o som autêntico dos despossuídos ... a sua forma de dizer 'Eu estou aqui, eu existo, eu não vou ser ignorado"'. Bater as caixas de Santa Teresa serve como um lembrete poderoso para ambos - católicos e evangélicos - de que essas terras continuam sob a custódia dos filhos de Santa.

Por um momento, a Santa Teresa recupera o espaço disputado e afırma o seu domínio sobre ele. Ela reúne os seus filhos e lembra que eles são uma grande família, que compartilha o mesmo território e a mesma fé religiosa. 0 que acontece durante a festa, portanto, é a comemoração dos laços que os associam, isto é, eles todos habitam as terras de Santa e são católicos. Neste sentido, de forma parecida com o que Hertz (1983) argumentou sobre a peregrinação de São Besse, que reúne moradores de vários povoados dos vales de Piedmont uma vez por ano, a festa, se não é "o último vestígio desses laços” (MacCLANCY 1994, p. 36), é certamente o mais evocativo. As visitas para a coleção de joia de forma significativa servem para reforçar os vínculos religiosos entre os moradores. Como Leal (2015, p. 7) argumenta sobre as festas do Divino na América do Norte, "as relações entre as pessoas envolvidas podem ser não muito fortes ou esporádicas; porém, há uma sensação de ser parte de um coletivo que a própria festa ajuda a criar".
As fortes conotações simbólicas do toque de caixa, portanto, podem também ser percebidas como tentativas de colocar todos os moradores sob os braços protetores da Santa padroeira. E até mesmo trazer de volta aqueles recém-convertidos que irão reconsiderar a sua conexão profunda com o catolicismo e a Santa. A presença física da Santa nos povoados, as cantigas e os toques de caixa pelo Batuque, espalham e ressoam por todo o vasto território de Santa Teresa, visando recuperar um pouco do território "perdido", atualmente ocupado por evangélicos.

\section{Considerações finais}

Como geógrafos sociais e humanísticos sugerem, já há muito tempo, “o espaço em si pode ser primordialmente dado, mas a organização e o significado do espaço é um produto de tradução social, de transformação, e de experiência” (SOJA, 1989, p. 79-80).

As terras de Santa Teresa, portanto, abrem-se como uma "arena sociopolítica" (HATUKA e KALLUS, 2007, p. 147) onde "fatos sociais estão localizados" (LOGAN, 2012, p. 508 apud ABBOTT, 1997, p. 1152, grifo nosso) e continuamente negociados. Essa negociação "ocorre em contextos, mas é conduzida à luz de estratégias, que implicam estruturações temporais pelas quais os depósitos do passado podem ser transformados em resultados futuros esperados" (PEEL, 2016, p. 542). Neste sentido, portanto, a constituição de um dado espaço é um processo continuo, aberto, e socialmente construído (LOOPMANS, COWELL e OOSTERLYNCK, 2012).

Os rituais e as práticas relacionadas que compõem a festa católica podem "reproduzir significados convencionais", 
tendo em conta o contexto sociorreligioso em constante mudança e a crescente influência das igrejas evangélicas, e mesmo assim "pressionam novas associações" (COMAROFF, 1985, p. 253). Nas palavras de Lefebvre: "espaço e organização política do espaço expressam relações sociais, mas também reagem a elas" (SOJA, 1989, p. 81 apud LEFEBVRE, 1970, p. 25). As "tensões dinâmicas" que se apresentam em diversas formas nas terras de Santa Teresa "se forçam sobre a experiência humana e exigem reconciliação, tornando assim a prática mais do que uma repetição habitual" (COMAROFF, 1985, p. 6). 0 toque de caixa e a oferta de joia, por exemplo, afirmam simbolicamente o alinhamento com a atual ordem política. Lutando para evitar quaisquer "transformações radicais" que os evangélicos possam causar, a maioria católica insiste em manter o status quo. Portanto, os comportamentos religiosos performativos "não são acidentais, mas intencionais e eles têm uma qualidade adicional de ser reflexivos" (WEST e BOWMAN, 2010, p. 279). As "normas, valores, e estruturações conceituais" que os católicos consideram como essencial para a manutenção da sua ordem religiosa e sociopolítica, "são reproduzidos por e para os atores" (ORTNER, 1984, p. 154).

Os católicos se sentem ameaçados de perder o controle sobre um território essencialmente religioso. Portanto, junto com esforços paralelos para obter a titulação do seu território coletivo, eles lutam para manter o território da Santa estritamente católico.

Constata-se que, por um lado, o artigo sugere que nem todos os participantes/ moradores envolvidos nas cerimônias religiosas e nas festividades da festa estão, ao mesmo tempo, conscientemente mapeando as reivindicações territoriais coletivas ou manifestando a convicção de sua ocupação legal da terra em seus antagonistas religiosos e territoriais: afınal, "a ação não é feita sob o controle absoluto da consciência” (LATOUR, 2005, p. 44). Por outro lado, o artigo tenta mostrar que em um mundo religioso que se transforma rapidamente, como o de Itamatatiua, os "atores religiosos" estão imersos num contexto social tenso e, em menor ou maior grau, por meio das suas ações são "capazes de reconfigurar a cena de debates públicos" (CLAVERIE, 2008, p. 8).

Como muitos identificam-se fortemente como "filhos da Santa", é por meio dessa identificação que eles reivindicam adesão a seu mundo social e se identificam em oposição a outros grupos. Práticas ligadas a festas religiosas que ocorrem em espaços públicos evocam memórias e concepções de um patrimônio compartilhado e renovam (ou não conseguem renovar) os laços sociais e as associações entre os diferentes atores. Mesmo para aqueles que escolhem não mais reconhecer esses laços, a festa de Santa Teresa serve como um lembrete visível e audível da presença católica e da afirmação dos seus direitos territoriais. Por sua própria ocorrência nas terras compartilhadas entre os filhos da Santa, a festa convida os moradores a participar dela e reforçam os laços que compõem o mundo social católico. Além disso, a festa se apresenta como uma das formas mais populares/participativas de ação política (sejam formais - em reuniões da comunidade, ou informais - produção cerâmica quilombola). Finalmente, sugeri que ao fortalecer os laços religiosos católicos, itamatatiuenses defendem simultaneamente sua identidade como quilombolas diante do estado nacional. 


\section{Referências}

AHLERT, M. Santos e encantados: religiosidade popular em Codó-MA. XVI JORNADA SOBRE ALTERNATIVAS RELIGIOSAS NA AMÉRICA LATINA, Anais... Punta del Este, p. 1-16, 2011.

. Carregado em saia de encantado: pessoa e transformação no terecô de Codó (Maranhão, Brasil). Etnográfica, v. 20, p. 275-294, 2016.

ALMEIDA, A. W. B. Os quilombolas e a base de lançamento de foguetes de Alcântara: laudo antropológico. Brasília: MMA. 2006.

BASTIDE, R. As religiões africanas no Brasil: contribuição a uma sociologia das interpenetrações de civilizações. 3. ed. São Paulo: Biblioteca Pioneira de Ciências Sociais, [1960] 1989.

BERLINER, D. When the object of transmission is not an object: An West African example (GuineaConakry). Res: Anthropology and Aesthetics, v. 51, p. 87-97, 2007.

BLANES, R. L.; SARRÓ, R. Geração, presença e memória: a igreja Tocoísta em Angola. Etnográfica, v. 19, n. 1, p. 169-187, 2015.

BLOCH, M. Essays on Cultural Transmission. LSE Monographs on Social Anthropology. Oxford e New York: Berg, 2005.

BOYER, V. A comunidade católica e a congregação evangélica: duas interpretações de um mesmo modelo sócio religioso. Tempo da Ciência, v. 23, n. 45, p. 27-37, 2016.

BURDICK, J. Looking for God in Brazil: the progressive catholic church in urban Brazil's religious arena. Berkeley: University of California Press, 1993.

CARNEIRO, R. B. C. 0 profeta, a palavra e a circulação do carisma pentecostal. Revista de Antropologia - USP, v. 54, n. 2, p. 1013-1049, 2011.

CHATZIKIDI, K. Children of the Land and Children of the Saint: Heritage, Religion, and Territoriality in a Brazilian Quilombo. 2018, $363 \mathrm{f}$.
Tese (Doutorado em Antropologia Social), Universidade de Oxford, Oxford, 2018.

CLAVERIE. É. Religion et politique. Terrain, v. 51, p. 4-9, 2008.

COMAROFF, J. Body of Power, Spirit of Resistance: The culture and history of a southafrican people. Chicago e London: The University of Chicago Press, 1985.

DULLO, E. A produção de subjetividades democráticas e a formação do secular no Brasil a partir da Pedagogia de Paulo Freire. 2013. Tese (Doutorado em Antropologia Social) - Museu Nacional, Universidade Federal do Rio de Janeiro/UFRJ, Rio de Janeiro, 2013.

DURKHEIM, É. The Elementary Forms of Religious Life. Trans. C. Cosman. Oxford e New York: Oxford University Press, [1912] 2001.

FERRETTI, M. M. R. Maranhão encantado: encantaria maranhense e outras histórias. São Luís: UEMA, 2000.

Querebentã de zomadonu: etnografia da Casa das Minas. São Luís: EDUFMA, 1996.

FRENCH, J. H. A tale of two priests and two struggles: Liberation Theology from dictatorship to democracy in the brazilian Northeast. The Americas, v. 63, n. 3, p. 409-443, 2007.

FRESTON, P. Evangélicos na política do Brasil: história ambígua e desafı ético. Curitiba: Encontrão, 1994.

FRY, P. Para inglês ver: identidade e política na cultural Brasileira. Rio de Janeiro: Zahar, 1977.

GALLANT, T. Turning the horns: Cultural metaphors, material conditions, and the peasant language of resistance in Ionian islands (Greece) during the nineteenth century. Society for Comparative Study of Society and History, v. 36, n. 4, p. 702-719, 1994.

HATUKA, T.; KALLUS, R. The myth of informal place-making: stitching and unstitching Atarim square in Tel Aviv. The Journal of Architecture, v. 12, n. 2, p. 147-164, 2007. 
HENDY, D. Noise: A Human History of Sound and Listening. London: Profile Books, 2014.

HERTZ, R. St B. A study of an alpine cult. In: WILSON, S. (Ed.) Saints and their Cults: studies in Religious Sociology and History. Cambridge: Cambridge University Press, [1913] 1983, p. 55-100.

LATOUR, B. Reassembling the Social: An Introduction to Actor-Network-Theory. Oxford e New York: Oxford University Press, 2005.

LEAL, J. Festivals, group making, remaking and unmaking. Ethnos: Journal of Anthropology, vol. 81, n. 4, p. 584-599, 2015.

LEFEBVRE, H. Critique of everyday life: The onevolume edition. London e New York: Verso, [1968] 2014.

LOGAN, J. Making a place for space: Spatial thinking in social science. Annual Review of Sociology, v. 38, p. 507-524, 2012.

LOOPMANS, M.; COWELL, G.; OOSTERLYNCK, S. Photography, public pedagogy and the politics of place-making in post-industrial areas. Social and Cultural Geography, v. 13, n. 7, p. 699-718, 2012.

LOPES, D. C. S. A base especial e as comunidades quilombolas de Alcântara. 64ª REUNIÃO da SBPC. Anais... São Luís do Maranhão, julho/2012.

LÖWY, M. The war of Gods: Religion and politics in Latin America. London e New York: Verso, 1996.

MACCLANCY, J. The construction of anthropological genealogies: Robert Hertz, Victor Turner and the study of pilgrimage. Revista JASO, v. 25, n. 1, p. 31-40, 1994.

MACGAFFEY, W. Religion and society in Central Africa: the BaKongo of lower Zaire. Chicago e London: The University of Chicago Press, 1986.

MACHADO, M. D. C.; BURITY, J. A ascensão política dos pentecostais no Brasil na avaliação de líberes religiosos. Revista de Ciências Sociais, v. 57, n. 3, p. 601-631, 2014.

MEYER, J. Catholic resistances in revolutionary Mexico during the religious conflict. In: GLE-
DHILL, J.; SCHELL, P. (Eds.) New approaches to resistance in Brazil and Mexico. Durham e London: Duke University Press, 2012, p. 165-183.

NORONHA, R. G. Dos quintais às prateleiras: imagens quilombolas e a produção da louça em Itamatatiua-MA. 2015. 289 f. Tese (Doutorado em Ciências Sociais) - Programa de Pós-Graduação em Ciências Sociais, Universidade do Estado do Rio de Janeiro, Rio de Janeiro/UERJ, 2015.

NUNES, P. P. Canelatiua, terra dos pobres, terra da pobreza: uma territorialidade ameaçada, entre a recusa de virar terra da base e a titulação como terra de quilombo. 2011. Tese (Doutorado em Antropologia) - Programa de Pós-Graduação em Antropologia, Universidade Federal Fluminense/UFF, Niteroi, 2011.

OLIVEIRA. Y. M. R. B. Território étnico: conflitos territoriais em Alcântara, Maranhão. 2011. 39 f. Dissertação (Mestrado em Planejamento Urbano e Regional) - Instituto de Pesquisa e Desenvolvimento, Universidade do Vale do Paraíba, São José dos Campos: São Paulo, 2011.

ORTNER, S. Theory in Anthropology since the Sixties: comparative studies in society and history, v. 26, n. 1, p. 126-166, 1984.

PAULA ANDRADE, M. P. Quilombolas: etnicidades emergentes? Subsídios para uma discussão. Ciências Humanas em Revista, v. 4, n. 1, p. 49-60, 2006

PEEL, J. D. Y. Time and difference in the anthropology of religion; The Frazer Lecture. Hau: Journal of Ethnographic Theory, Oxford, 9 May 2000, v. 6, n. 1, p. 533-551, 2016.

PEREIRA JÚNIOR, D. Tradição e identidade: A feitura de louça no processo de construção de identidade da comunidade de Itamatatiua, AlcântaraMA. In: MARTINS, C. C.; CANTANHÊDE FILHO, A.; VASCONCELOS, A. G.; ARAUJO, H. C. A. (Orgs.) Insurreição de saberes: práticas de pesquisa em comunidades tradicionais. Manaus: UEA, 2011.

. Territorialidades e identidades coletivas: uma etnografia de Terra de Santa na Baixada Maranhense. 2012. 151 f. Dissertação (Mestrado em Antropologia), Programa de Pós-Graduação 
em Antropologia, Universidade Federal da Bahia/ UFMA, Salvador, 2012.

SARRÓ, R. The Politics of Religious Change on the upper Guinea Coast: Iconoclasm done and undone. London: International African Institute/ Edinburgh University Press, 2008.

SAULE JÚNIOR, N. et al. A situação dos direitos humanos das comunidades negras e tradicionais de Alcântara. 0 direito à terra e à moradia dos remanescentes de quilombos de Alcântara, MA Brasil. Relatório da Missão da Relatoria Nacional do Direito à Moradia Adequada e à Terra Urbana. São Paulo: Instituto Pólis, 2003.

SAULE JÚNIOR, N.; CARDOSO, P. M. C. 0 direito à moradia no Brasil: violações, práticas positivas e recomendações ao governo brasileiro. Relatório da Missão Conjunta da Relatoria Nacional e da ONU. São Paulo: Instituto Pólis, 2005.

SCOTT, J. Weapons of the weak: Everyday Forms of Peasant Resistance. New Haven e London: Yale University Press, 1985.

SOJA, E. Postmodern Geographies: the reassertion of space in critical social theory. London e New York: Verso, 1989.

VOEGELIN, S. Listening to Noise and Silence: Towards a philosophy of sound art. New York e London: Continuum, 2011.

WEST, S.; BOWMAN, M. Heritage as performance. In: WEST, S. (Ed.) Understanding heritage in practice. Manchester e New York: Manchester University Press, 2010, p. 277-312. 
RESUMO

0 presente artigo discute uma das formas com quais quilombolas católicos do litoral norte maranhense defendem o seu território coletivo chamado "Terras de Santa Teresa", dos seus principais adversários religiosos e territoriais: os evangélicos. Residentes católicos (historicamente o grupo religioso da maioria esmagadora da população na região) estão lutando contra o surgimento e a influência crescente de igrejas pentecostais e tentam reforçar o catolicismo e os laços religiosos entre os residentes. No intuito de discutir esse tema, o artigo analisa as dinâmicas de agregação e mobilização do capital religioso no nível local. Defendo que estas dinâmicas se materializam principalmente nos preparativos para, e durante, as celebrações anuais do festejo da padroeira Santa Teresa de Jesus. Será mostrado que na defesa e manutenção da sua identidade católica, os quilombolas estão ao mesmo tempo defendendo o seu território comum e as suas tradições religiosas e culturais.

\section{PALAVRAS-CHAVE}

Territorialização quilombola; Conflitos religiosos e territoriais

\section{ABSTRACT}

This article focuses on some of the ways Catholic quilombolas of the lands of Santa Teresa engage with their collectively inhabited territory vis-à-vis what they perceive as their main religious and land antagonists, namely Evangelical Christians. Catholic residents (historically being the single major religious group in the area) are trying to fight back against the emergence and growing influence of Pentecostal churches and reinforce Catholicism and religious ties among Catholic residents. It will be argued that the aggregating and mobilising dynamics of religious capital at the local level, primarily materialises in the preparations for and during the annual celebrations for the local patron saint and owner of the lands, Santa Teresa de Jesus. It will be showed that in defending and maintaining a Catholic identity, residents are simultaneously defending their communal territory and their cultural and religious traditions.

\section{KEYWORDS}

Quilombo territoriality, religious and territorial conflicts 
